ORIGINAL ARTICLE

\title{
Serum Level of Vitamin A in Breast Cancer Patients and Apparently Healthy Women of Lahore, Pakistan
}

\author{
MAHWISH SHAHZAD ${ }^{1}$, BUSHRA IFTIKHAR ${ }^{2}$, MEHWISH IFTIKHAR ${ }^{3}$, SADIA NAZEER ${ }^{4}$, RABIA AKHTAR CHEEMA \\ ${ }^{1}$ Assistant Professor, Department of Biochemistry, Lahore Medical and Dental College, \\ ${ }^{2,3}$ Assistant Professors, Department of Biochemistry, Azra Naheed Medical College Lahore, \\ ${ }^{4}$ Associate Professor Department of Physiology, Lahore Medical and Dental college, \\ ${ }^{5}$ Assistant Professor, Department of Physiology, Independent Medical college Faisalabad \\ Correspondence to Dr. Mahwish Shahzad, Email: mehwish.shahzad@lmdc.edu.pk Tel.0300-4127466
}

\begin{abstract}
Background: Breast cancer is the second leading cause of death among women worldwide. In Asia, Pakistan has the highest number of patients of breast cancer. Chronic inflammation and hormonal imbalances contribute to the redox disruption thus increasing ROS that changes gene expression resulting in carcinogenesis. Antioxidants like Vitamin A may help reduce tissue-level inflammation through different mechanisms by maintaining redox balance within the tissue.

Methods: This cross sectional comparative study was used to measure the serum level of vitamin A in breast cancer patients and in apparently healthy women of same age group to determine the involvement, if any, of this vitamin in breast cancer etiology. Out of 90 women that were recruited, 60 were breast cancer patients and 30 were apparently healthy women.

Results: Vitamin A level in serum was measured by Enzyme Linked Immunosorbant Assay (ELISA). Serum vitamin A level was lower than the WHO reference values $(30-90 \mu \mathrm{g} / \mathrm{dl})$ in all patients $(18.62 \pm 4.43 \mu \mathrm{g} / \mathrm{dl})$ and apparently healthy women $(19.59 \pm 3.40 \mu \mathrm{g} / \mathrm{dl})$. Although no difference was seen between patients and controls $(p=0.274)$, nevertheless, more women $(28.3 \%)$ were severely deficient in vitamin $A$ than normal $(6.7 \%)$ women. Increase in age significantly decreased vitamin A in both normal and breast cancer patients. Vitamin A level in serum was generally low, when matched with international reference values in patients than apparently healthy women.

Conclusion: It is concluded that deficiency of vitamin A might lead to metabolic disturbances that can contribute to the development of cancers like breast cancer.

Keywords: breast cancer, ROS, vitamin A, anti oxidants
\end{abstract}

\section{INTRODUCTION}

Cancer of breast is one of the most frequently diagnosed cancers and is also the major cause of death in females worldwide ${ }^{1}$. In Pakistan, it is more common at a young age as compared to the west where it is more common after 60 years. Incidence of breast cancer is growing at an alarming rate in Pakistan as approximately one in every nine Pakistani women is likely to suffer from breast cancer showing an incidence rate of 50/100,0002. Carcinoma of breast is a complex disease that can occur due to multiple factors including reproductive, genetic and environmental factors $^{3}$. In this condition, oxidative stress is increased due to the disruption of redox homeostasis ${ }^{4}$. There is accumulation of free radicals due to their increased rate of production as compared to rate of excretion from the body. As a consequence, the transcription factors that are responsible for the regulation of genes involved in the development of chronic inflammation get activated hence promoting carcinogenesis ${ }^{5,6}$.

Retinoic acid (RA) is the primary endogenous vitamin A metabolite responsible for majority of its biological effects. Receptors of vitamin $A$ are retinoic acid receptors (RARs) or retinoid $X$ receptors (RXRs). RA- receptor complex, binds to RA response element $s$ in the promoter regions of target genes altering the gene expression hence

Received on 14-04-2021

Accepted on 03-09-2021 producing biological effects ${ }^{7}$. RA and a variety of other retinoids have been shown to modulate the growth of epithelial cells of breast, mammary tumor cells in animal models and arrest the growth of human mammary cancer cells in vitro ${ }^{8,9,10}$.

Estrogen receptor positive $(\mathrm{ER}+)$ breast cancer cell lines have shown more response to RA-mediated growth inhibition than estrogen receptor negative (ER-) cell lines but why this response is absent or low in ER- mammary cells is not clear ${ }^{11}$. RARs have been suggested to be responsible for the growth inhibitory effects of retinoids ${ }^{12}$. Quantity of receptor ligands partially controls RA-receptormediated transcription, hence the ability and capacity of cells to produce RA may have an integral role in regulating the growth of certain cancer cells. Not much is known regarding RA synthesis by different cancer cells. Results of recent studies indicate that some $\mathrm{ER}+$ growth responsive cells have greater RA catabolic activity than ER(nonresponsive) cells. Thus, metabolically, there is evidence to suggest that differences in RA catabolism may be associated with variation in response between $E R+$ and ER- mammary cell lines ${ }^{13}$.

The role of RA synthesis in breast cancer is, however, not known. The responsiveness of cells to retinol $(\mathrm{ROH})$ has important biological implications given that $\mathrm{ROH}$ is the chief substrate for retinoic acid synthesis. The importance of cellular RA synthesis is evidenced by the observations that the more metabolic conversion of ROH to RA the more is the biological responsiveness of cells to $\mathrm{ROH}$. Limited evidence suggests that $\mathrm{ROH}$ modulates breast cancer cell 
growth to a lesser extent than RA. Given the regulatory role of RA and the presence of its metabolic substrate $\mathrm{ROH}$ in excess, determining the extent of RA synthesis in normal versus cancerous cells is an important aspect of understanding the role of endogenous retinoids in cancer and has implications for the use of retinoids as therapeutic agents ${ }^{14}$. In vitro, studies show that retinoids, in particular 9-cis-RA, restrict the growth of estrogen receptor positive cells through blocking cell cycle ${ }^{15}$, but have no effect on ER negative human breast cancer cells ${ }^{16}$. It has been demonstrated that ER-negative cells show lower levels of RAR- $\beta$ as compared to their matched ER-positive cells and they exhibit retinol-induced growth inhibition when transfected with RAR- $\beta^{15}$. Preclinical studies show that all trans retinoic acid (ATRA) inhibits cell cycle and arrests proliferation in mammary cancer cells by modulating cyclindependent kinase inhibitors and dephosphorylation of retinoblastoma protein ${ }^{15}$.

\section{PATIENTS AND METHODS}

The study was approved by the advanced studies and research board of UHS. The purpose of the study was explained to all participants and investigation was carried out with their written consent. A total of 60 newly diagnosed patients of breast cancer, after confirmation of diagnosis on histopathology, were recruited from Inmol Hospital, Lahore. Selected patients were of stages (TNM) 1 and 2. Five out of 60 patients had partial mastectomy done one month before the collection of samples. Blood samples of patients were collected before initiating chemotherapy or radiotherapy. The subjects were ranging in age 20-60 years. They had all a body mass index of $23.1 \pm 3.85$. None of them had concomitant diseases such as diabetes mellitus, liver disease, hypertension and previous history of any other cancer. None of them was using vitamin supplements. Thirty healthy age matched (between 20 and 60 years) women were selected as controls. They had all a $\mathrm{BMI}$ of $21.0 \pm 2.6$ and were considered normal weight. None of the controls had a previous history of breast cancer and other cancer-related diseases. A questionnaire with epidemiologic information on demographic and lifestyle factors, personal and medical history, and family history of breast cancer was completed for each participant.

Five milliliters of blood were taken from the antecubital vein of each subject, under aseptic conditions, in gel coated vacutainer tube. After centrifugation, serum was aliquoted and stored at -80 degree Celsius until analyzed. Serum vitamin A levels were estimated by sandwich enzyme linked immunosorbant assay (ELISA) using automated EIA analyzer (Bio-Rad Laboratories, Hercules, CA, USA) with commercially available human vitamin A ELISA kit.

Statistical analysis: For the purpose of comparison and analysis they were divided into subgroups according to their ages. Group A comprised of female patients of CA breast and was subdivided into two groups $A 1$ and $A 2$. In A1 women were of ages 20 - 40 yrs $(n=30)$ and in $A 2$ women were of 41 - 60 yrs $(n=30)$. Group B was the control group (females without CA breast) and was subdivided into $B 1$ and B2. In B1 women were of ages $20-40$ yrs $(n=15)$ and in B2 women were of $41-60$ yrs $(n=15)$. The data were entered and analyzed using IBM SPSS (Statistical Package for Social Sciences) version 20.0. A p-value of < 0.05 was considered statistically significant for all purposes. Two way ANOVA was used to check relationship between vitamin $A$ levels and age of subgroups of patients and controls.

Table 1: Serum level of vitamin a $(\mu \mathrm{g} / \mathrm{dl})$ in patients and controls according to age groups

\begin{tabular}{|l|c|c|c|}
\hline Age & Groups & Mean \pm SD & p value \\
\hline Group A (Patients) & $20-60 \mathrm{yrs}$ & $18.62 \pm 3.40$ & \multirow{2}{*}{$0.274 \mathrm{a}$} \\
\cline { 2 - 3 } Group B (Controls) & & $19.59 \pm 3.40$ & \multirow{2}{*}{$0.737 \mathrm{~b}$} \\
\hline Group A1 and A2 (Patients) & $20-40 \mathrm{yrs}$ & $17.55 \pm 13.7$ & \multirow{2}{*}{$0.06 \mathrm{a}$} \\
\cline { 2 - 3 } & $41-60 \mathrm{yrs}$ & $13.27 \pm 7.02$ & $23.4 \pm 16.2$ \\
\hline
\end{tabular}

a p-value generated by Independent Sample "t"-Test

b p-value generated by Mann-Whitney U Test

p-value $\leq 0.05$ is considered statistically significant

Table 2: Result of two-way anova tests of between-subjects of different age groups and their vitamin a levels in apparently Healthy and Ca breast patients

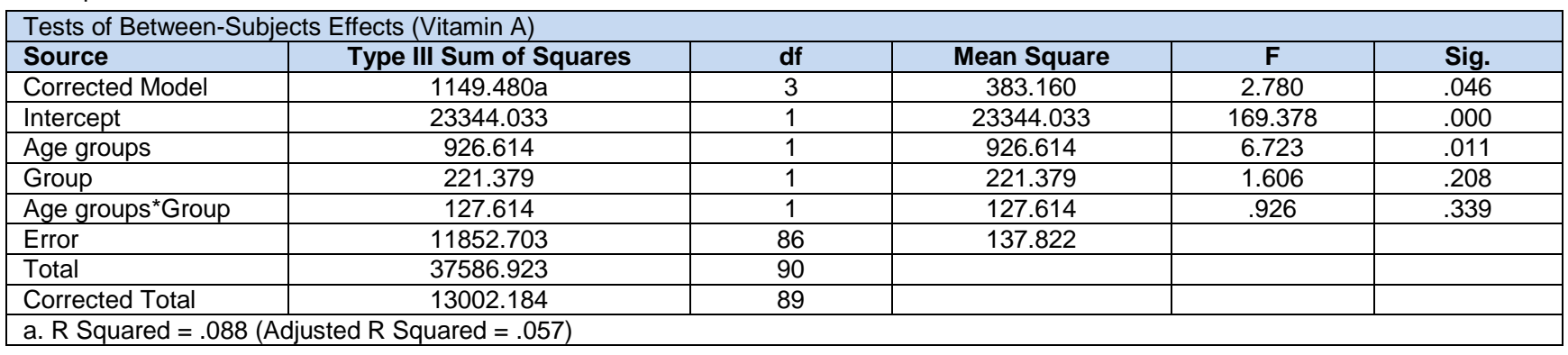


Figure 1: Plot of mean score of vitamin A for each combination of groups (patients and controls) and subgroups on the basis of Age (based on two-way ANOVA)

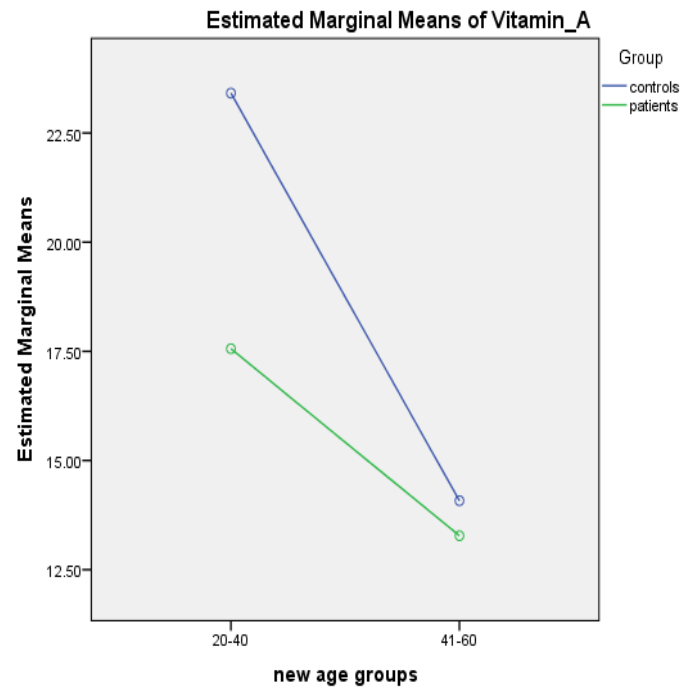

The plot of mean score of vitamin A for each combination of groups (patients and controls) and subgroups on the basis of Age (20-40 and 41-60 years) is plotted in a line graph as shown above. It is providing a good graphical presentation of our results obtained by twoway ANOVA. No interaction effect can be seen as graph is showing parallel lines of mean levels of dependant variable (Vitamin A) in both groups on the basis of age. If the lines appeared to be non-parallel and crossed each other then we could interpret this line graph as some significant interaction on the basis of two way ANOVA. Also, it is clearly showing that the value of vitamin $A$ decreases as the age is advanced (increased) both in patients and normal subjects.

\section{DISCUSSION}

In the current study, we recruited females from 20-60 years of age having breast cancer with no history of any multivitamin therapy. We could not follow up the patients to document mortality rate by survival analysis due to limited time and resources. In this study on women (breast cancer patients and healthy women) from Lahore, serum level of vitamin $A$, when compared to international standard reference values given by WHO (2011), was found to be deficient in $17(28.3 \%)$ patients while only $2(6.7 \%)$ individuals in controls were found to have low levels and rest of the controls had values more or less within normal range of vitamin A. According to international standard reference values, normal range of vitamin $A$ in serum is $30-$ $90 \mu \mathrm{g} / \mathrm{dl}(1.05-3.15 \mu \mathrm{mol} / \mathrm{L})$ and value of less than $20 \mu \mathrm{g} / \mathrm{dl}$ $(<0.7 \mu \mathrm{mol} / \mathrm{L})$ is considered as vitamin A deficiency ${ }^{17}$. In this study, mean vitamin A level of apparently healthy women was $19.59 \pm 3.40 \mu \mathrm{g} / \mathrm{dl}$ and of breast cancer patients was $18.62 \pm 4.43 \mu \mathrm{g} / \mathrm{dl}$ (Table 1$)$. In patients the levels were $5.21 \%$ low as compared to the controls but this difference was not significant. We observed deficient values in both patients and controls of $>40$ years age groups as compared with $<40$ years age group. An inverse association was found between age and the vitamin $A$ levels in breast cancer patients in current study and this association was statistically significant ( $p$ value $=0.011$ ).

Ramaswamy and coworkers reported variable levels of vitamin $A$ in different populations and age groups. According to them the serum levels of beta-carotene and vitamin $A$ have shown a significant difference in all the epithelial cancers compared with the controls ${ }^{18}$. In a prospective study, the plasma retinol levels were not found to be related to the risk of breast cancer. In that study, mean levels of cases and controls were reported as $479 \mu \mathrm{g} / \mathrm{L}$ and $485 \mu \mathrm{g} / \mathrm{L}$, while in our study these were $18.62 \pm 4.43 \mu \mathrm{g} / \mathrm{dl}$ and $19.59 \pm 3.40 \mu \mathrm{g} / \mathrm{dl}$ in patients and controls respectively ${ }^{19}$. Wald, et al. (1984) documented a significant negative correlation between serum vitamin $A$ (retinol) concentrations and risk of cancers but carotene values showed a tendency to be lower in the normal controls. Another study done on nurses' health showed an inverse relationship between vitamin $A$ and $C A$ breast in premenopausal women. Strong inverse associations were found for increasing quintiles of total vitamin A among premenopausal women who had a positive family history of breast cancer $^{20}$. In our study, positive family history of breast cancer was significant in patients as compared to controls $(p=0.034)$ which was similar to Zhang et al. (2009) findings.

One factor, that we could not get a clear cut relationship between vitamin $A$ and breast cancer was that the level of this vitamin was in the lower range of normal values even in control women which made the difference insignificant. Also we had few samples analyzed because of the constraints of funds and time. Further studies are needed. Based on our results and reported literature we can't say definitely either low or high levels of vitamin A have a clear association with breast cancers. From these results we can say that the nutritional status for vitamin $A$ of women of this study was compromised and that age is a factor in this regard. We suggest a comprehensive study on the status of vitamin $A$ in our population taking into consideration the population income group, nutritional habits, life styles and disease status.

\section{CONCLUSION}

Breast cancer is associated with a high content of free radicals, which might be related to low levels of antioxidants. There is a probability that nutritional consumption of vitamin $A$ is compromised which is also shown by our results in breast cancer patients. Significant low levels vitamin A may result into severe complications. Age in this connection is also a factor. But due to small sample size of our study and discrepancies in the available earlier experimental results, there is currently a need for a proper population based study on the role of vitamin $A$ in diseases and their supplementation for the prevention of chronic diseases including breast cancer.

Limitations: Small sample size because of financial constraint was a limitation

Acknowledgements: We would like to acknowledge Prof. Dr. Khalid Pervez lone and Mr. Shabbir Hussain for their guidance, support and help. 
Conflict of interest: None

\section{REFERENCES}

1. Jemal, A., Center, M. M., Desantis, C. \& Ward, E. M. 2010. Global patterns of cancer incidence and mortality rates and trends. Cancer Epidemiol. Biomarkers Prev., 19(8): 18931907.

2. Nisar, M. \& Zamir, T. 2015. Assessing Breast Cancer Incidence and Risk Factors from 2005-2015 in Pakistan. JBUMDC, 5(4): 157.

3. Parkin, D., Whelan, S., Ferlay, J., Teppo, L. \& Thomas, D. 2002. Cancer incidence in five continents Vol. VIII. IARC Sci. Publ., 155.

4. Ramírez-Expósito, M. J., Sánchez-López, E., Cueto-Ureña, C., Dueñas, B., Carrera-González, P., Navarro-Cecilia, J., Mayas, M. D., De Saavedra, J. M. A., Sánchez-Agesta, R. \& Martínez-Martos, J. M. 2014. Circulating oxidative stress parameters in pre-and post-menopausal healthy women and in women suffering from breast cancer treated or not with neoadjuvant chemotherapy. Exp. Gerontol., 5834-42.

5. Reuter, S., Gupta, S. C., Chaturvedi, M. M. \& Aggarwal, B. B. 2010. Oxidative stress, inflammation, and cancer: how are they linked? Free Radic. Res., 49(11): 1603-1616.

6. Vera-Ramirez, L., Sanchez-Rovira, P., Ramirez-Tortosa, M. C., Ramirez-Tortosa, C. L., Granados-Principal, S., Lorente, J. A. \& Quiles, J. L. 2011. Free radicals in breast carcinogenesis, breast cancer progression and cancer stem cells. Biological bases to develop oxidative-based therapies. Crit. Rev. Oncol. Hematol., 80(3): 347-368.

7. Van Der Saag, P. 1996. Nuclear retinoid receptors: mediators of retinoid effects. Eur. J. Clin. Nutr., 50 S24.

8. Moon, R. C. \& Constantinou, A. I. 1997. Dietary retinoids and carotenoids in rodent models of mammary tumorigenesis. Breast Cancer Res. Treat., 46(2-3): 181-189.

9. Agadir, A., Chen, G.-Q., Bost, F., Li, Y., Mercola, D. \& Zhang, X.-K. 1999. Differential effect of retinoic acid on growth regulation by phorbol ester in human cancer cell lines. J. Biol. Chem., 274(42): 29779-29785.

10. Seewaldt, V. L., Dietze, E. C., Johnson, B. S., Collins, S. J. \& Parker, M. B. 1999. Retinoic acid-mediated G1-S-phase arrest of normal human mammary epithelial cells is independent of the level of p53 protein expression. Cell Growth Differ., 10(1): 49-60.

11. Takatsuka, J., Takahashi, N. \& De Luca, L. M. 1996. Retinoic acid metabolism and inhibition of cell proliferation: an unexpected liaison. J. Cancer Res. Oncobiol., 56(4): 675-678.

12. Pratt, M. C., Deonarine, D., Teixeira, C., Novosad, D., Tate, B. F. \& Grippo, J. F. 1996. The AF-2 region of the retinoic acid receptor a mediates retinoic acid inhibition of estrogen receptor function in breast cancer cells. Biochem. Mol. Biol. J., 271(34): 20346-20352.

13. Okamoto, K., Andreola, F., Chiantore, M. V., Dedrick, R. L. \& De Luca, L. M. 2000. Differences in uptake and metabolism of retinoic acid between estrogen receptor-positive and-negative human breast cancer cells. Cancer Chemother. Pharmacol., 46(2): 128-134

14. Hayden, L. J. \& Satre, M. A. 2002. Alterations in cellular retinol metabolism contribute to differential retinoid responsiveness in normal human mammary epithelial cells versus breast cancer cells. Breast Cancer Res. Treat., 72(2): 95-105.

15. Doldo, E., Costanza, G., Agostinelli, S., Tarquini, C., Ferlosio, A., Arcuri, G., Passeri, D., Scioli, M. G. \& Orlandi, A. 2015. Vitamin A, cancer treatment and prevention: the new role of cellular retinol binding proteins. Res. Bio. Med. Int., 2015.

16. Ribeiro, M. P., Santos, A. E. \& Custódio, J. B. 2014. Interplay between estrogen and retinoid signaling in breast cancerCurrent and future perspectives. Cancer letters, 353(1): 1724.

17. W. H. Organization, 2011. Serum retinol concentrations for determining the prevalence of vitamin A deficiency in populations.

18. Ramaswamy, P. G., Krishnamoorthy, L., Rao, V. R. \& Bhargava, M. K. 1990. Vitamin and provitamin A levels in epithelial cancers: a preliminary study.

19. Wald, N., Boreham, J., Hayward, J. \& Bulbrook, R. 1984. Plasma retinol, $\beta$-carotene and vitamin $E$ levels in relation to the future risk of breast cancer. Br. J. Cancer, 49(3): 321.

20. Zhang, C. X., Ho, S. C., Chen, Y. M., Fu, J. H., Cheng, S. Z. \& Lin, F. Y. 2009. Greater vegetable and fruit intake is associated with a lower risk of breast cancer among Chinese women. Int. J. Cancer Manag., 125(1): 181-188. 